\title{
Prognostic factors for chronic headache
}

\author{
A systematic review
}

OPEN

Katrin Probyn, MPH

Hannah Bowers, PhD

Fiona Caldwell, MA

Dipesh Mistry, PhD

Martin Underwood, MD

Manjit Matharu, MD

Tamar Pincus, PhD

On behalf of the CHESS

Team

Correspondence to

K. Probyn:

Katrin.probyn@rhul.ac.uk

Editorial, page 224

Supplemental data at Neurology.org

\section{ABSTRACT}

Objective: To identify predictors of prognosis and trial outcomes in prospective studies of people with chronic headache.

Methods: This was a systematic review of published literature in peer-reviewed journals. We included (1) randomized controlled trials (RCTs) of interventions for chronic headache that reported subgroup analyses and (2) prospective cohort studies, published in English, since 1980. Participants included adults with chronic headache (including chronic headache, chronic migraine, and chronic tension-type headache with or without medication overuse headache). We searched key databases using free text and $\mathrm{MeSH}$ terms. Two reviewers independently extracted data and assessed the methodologic quality of studies and overall quality of evidence identified using appropriate published checklists.

Results: We identified 16,556 titles, removed 663 duplicates, and reviewed 199 articles, of which 27 were included in the review-17 prospective cohorts and 10 RCTs with subgroup analyses reported. There was moderate-quality evidence indicating that depression, anxiety, poor sleep and stress, medication overuse, and poor self-efficacy for managing headaches are potential prognostic factors for poor prognosis and unfavorable outcomes from preventive treatment in chronic headache. There was inconclusive evidence about treatment expectations, age, age at onset, body mass index, employment, and several headache features.

Conclusions: This review identified several potential predictors of poor prognosis and worse outcome postinterventions in people with chronic headache. The majority of these are modifiable. The findings also highlight the need for more longitudinal high-quality research of prognostic factors in chronic headache. Neurology ${ }^{\circledR}$ 2017;89:291-301

\section{GLOSSARY}

BMI = body mass index; $\mathbf{C D H}=$ chronic daily headache; GRADE = Grading of Recommendations Assessment, Development and Evaluation; HIT = Headache Impact Test; HMSE = headache management self-efficacy; RCT = randomized controlled trial.

Chronic headache-headache occurring on 15 or more days per month for at least 3 months ${ }^{1}$ is a major cause of pain and disability. Chronic migraine affects around $1 \%-4 \%$ of the population $^{2,3}$ and chronic tension-type headache about $2.2 \% .{ }^{4}$ Approximately $25 \%-50 \%$ of those affected also have medication overuse headache, which has a population prevalence of $1 \% .^{5}$ Chronic headache is a severely disabling long-term condition, with higher symptom frequency and severity than episodic headache. ${ }^{6}$

A wide range of demographic, clinical, psychological, and social factors may affect prognosis and treatment outcome for people with chronic headache. ${ }^{7,8}$ Our aims were to identify factors that predict poor prognosis or are associated with differential treatment outcomes from

From the Department of Psychology (K.P., H.B., F.C., T.P.), Royal Holloway, University of London; Warwick Clinical Trials Unit (D.M., M.U.), Warwick Medical School, University of Warwick, Coventry; and Headache Group (M.M.), Institute of Neurology and The National Hospital for Neurology and Neurosurgery, Queen Square, London, UK.

Coinvestigators are listed at Neurology.org.

Go to Neurology.org for full disclosures. Funding information and disclosures deemed relevant by the authors, if any, are provided at the end of the article. The Article Processing Charge was funded by the authors.

This is an open access article distributed under the terms of the Creative Commons Attribution-NonCommercial-NoDerivatives License 4.0 (CC BY-NC-ND), which permits downloading and sharing the work provided it is properly cited. The work cannot be changed in any way or used commercially without permission from the journal. 
preventive treatment in patients with chronic headache. Factors can be differentiated between predictors of prognosis and moderators or mediators of treatment outcome. ${ }^{9}$ Specifically; predictors are factors, measured at baseline, that affect outcome but do not interact with the intervention; moderators are factors, measured at baseline, that interact with the treatment to change outcome for a subgroup of participants; mediators are factors measured during or after treatment that influence outcomes, with or without interaction with the treatment.

Identifying those factors may improve the effectiveness and cost-effectiveness of future interventions for people living with chronic headache. ${ }^{10}$

METHODS This study was prospectively registered with the International Prospective Register of Systematic Reviews; PROSPERO 2015: CRD42015019848 (available at crd.york.ac.uk/ PROSPERO/display_record.asp?ID=CRD42015019848).

Identification of studies. We searched for English-language publications reporting randomized controlled trials (RCTs) or prospective cohort studies that reported on predictors, moderators, or mediators of outcome from peer-reviewed journals in Cochrane, MEDLINE/PubMed, Embase, PsychINFO, Web of Science, and ASSIA, supplemented by backward citation tracking, from January 1, 1980, to February 12, 2015. We updated the search on June 14, 2016 (appendix e-1 and table e-1 at Neurology.org).

We included RCTs with at least 20 patients per treatment arm at follow-up (in line with previous research ${ }^{11}$ ) that either (1) investigated moderators or mediators of outcome using a priori hypotheses or (2) analyzed subgroups post hoc; and prospective cohort studies that measured factors at baseline and used a timeline to outcomes at follow-up to explore the associations between factors. Study participants were adults (18 years and over) and had chronic headache as defined by the International Classification of Headache Disorders ${ }^{1}$ with at least 15 headache days/ month for at least 3 months. We included chronic headache, chronic migraine, and chronic tension-type headache, with or without medication overuse headache.

In RCTs that included episodic headache patients, at least $50 \%$ of the study population had to be chronic headache patients. In prospective cohort studies, prognostic factors had to be analyzed and reported separately for chronic headache. We excluded cross-sectional and prevalence studies, case-control studies, and studies that included any other chronic pain conditions. We used EPPI reviewer4 software to screen studies for inclusion/exclusion by title and abstract. Articles for possible inclusion were assessed in full. We extracted data from included studies on separate predeveloped forms for RCTs and prospective cohort studies separately, including the following items: author, year, title, headache type, number of participants, description of intervention and control groups (as applicable), factors assessed as potential predictors/moderators/mediators, outcomes, and results.

Quality assessment. RCTs were quality assessed with a set of questions adapted from the Cochrane Collaboration risk of bias tool $^{12}$ and we excluded any studies that yielded a high risk of bias score. We assessed sequence generation, allocation concealment, incomplete outcome data, and blinding of outcome assessment. Studies scoring $4-5$ points were considered high quality, studies scoring 2-3 were considered medium quality, and studies that scored 0 or 1 were excluded. We assessed the level of evidence from subgroup analyses using the methodologic criteria for the assessment of moderators in systematic reviews of RCTs, ${ }^{13}$ which score for a priori planned analysis, theory-driven selection of factors, measurement of moderators prior to randomization, quality of moderator measures, and explicit test of the interaction between moderator and treatment. Studies complying with all 5 criteria were considered as providing confirmatory evidence; those complying with criteria 3, 4, and 5 as providing exploratory evidence. All other studies were classified as providing insufficient evidence.

Methodologic quality coding of prospective cohort studies was carried out based on recommendations for evaluation of the quality of prognosis studies in systematic reviews. ${ }^{14} \mathrm{We}$ assessed if sampling frame and recruitment been described adequately, the frequency of loss to follow-up from sample, definition of outcomes of interest, if appropriate analyses were used, if statistical reporting was appropriate, if sample size was appropriate for statistical analysis, if measurement of all important confounders was adequately valid and reliable, and if most important baseline measures were included. We scored 1 point per item; studies scoring $\leq 5$ points were considered low quality, studies scoring 6-9 points medium quality, and those scoring $\geq 10$ out of 14 possible points were considered high quality.

Finally, we assessed the overall quality of evidence for each potential factor with an adapted version of the Grading of Recommendations Assessment, Development and Evaluation (GRADE) framework, ${ }^{15}$ considering phase of investigation, methodologic quality per studies, and potential inconsistency, indirectness, imprecision, publication bias, dose response effect, or potentially large effect sizes across all studies. We downgraded factors for inconsistency when estimates of the prognostic factor's association with outcomes varied in direction. We downgraded factors for indirectness when the included sample of most studies only represents a subset (i.e., chronic migraine only, or chronic tension-type headache only, or medication overuse headache only) of the whole population of interest (chronic headache). We downgraded quality for imprecision if the evidence was generated by few studies involving a small number of participants and most of the studies provided imprecise results or no relevant statistics or if evidence only was provided by single studies.

Data synthesis. Because of the high heterogeneity among studies regarding treatment and investigated prognostic factors, it was not possible to pool studies in a meta-analysis. We therefore present a narrative synthesis of the results, considering the overall quality of evidence as proposed by Huguet et al. ${ }^{15}$

RESULTS We identified 16,556 titles through database searches and removed 633 duplicates. A total of 15,923 studies were screened by title and abstracts and 15,724 records excluded. The remaining records were grouped into RCTs (126) and prospective cohort studies (73). After full text assessment, 27 studies were included (10 RCTs with subgroup analysis $^{16-25}$ and 17 prospective cohorts ${ }^{5,26-41}$ ) (figure).

Characteristics of included studies. Eight studies tested a general population of "chronic headache," 8 are specifically on "chronic migraine," 5 include participants with "chronic daily headache," 3 are 


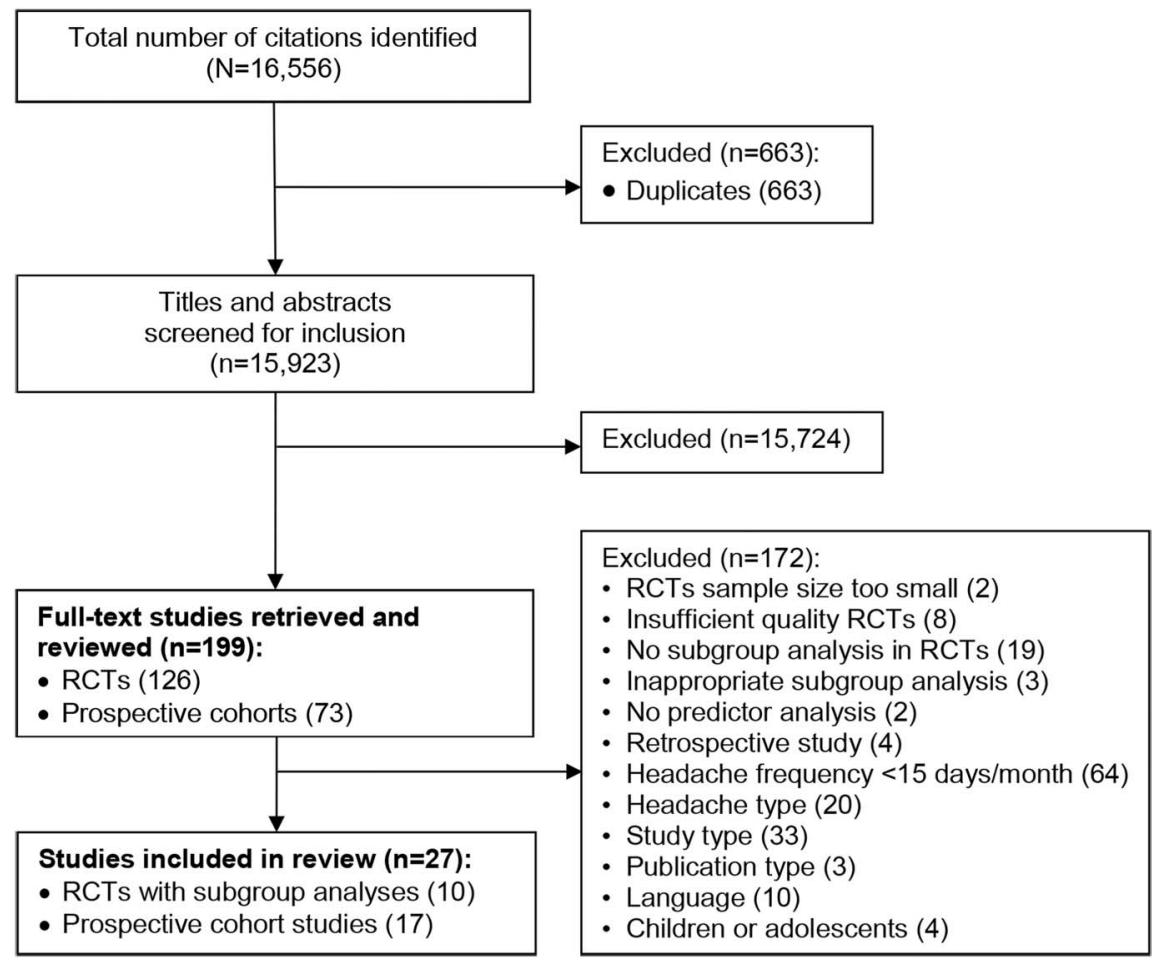

$\mathrm{RCT}=$ randomized controlled trial.

specifically on "chronic tension type headache," and 3 on "chronic headache forms with medication overuse." Outcomes assessed include headache-specific measures (headache frequency, intensity, and duration of headache attacks); measures of quality of life or headache-related disability; mood; coping and headache management self-efficacy (HMSE); days off work; persistence of chronic headache or reverting to episodic headache; relapse rates (from withdrawal therapy); or response to preventive treatment in responder analyses (table 1 ).

Randomized controlled trials. Six of the 10 included trials involved medication in at least one of their treatment arms. ${ }^{16,20-25}$ Two studies examined subgroups in trials of psychological interventions, ${ }^{17,20}$ with one study doing this alongside medication treatment. ${ }^{20}$ One study assessed manual therapy, ${ }^{18}$ while 3 studies looked at acupuncture. ${ }^{19,22,23}$ Within the subgroup analyses in included RCTs, only 3 studies assessed potential moderators by providing an explicit interaction test with treatment. ${ }^{19,20,23}$ All other RCTs provide, in the absence of an interaction test, findings about predictors of outcome only.

Prospective cohorts. The majority of the prospective cohort studies assessed potential predictors of response to treatment or withdrawal therapy outcome $(\mathrm{n}=11)$, while 6 assessed predictors of prognosis, independent of treatment.
Methodologic quality. Of the 10 RCTs with subgroup analyses and of at least medium overall methodologic quality (table 2), only one study provided confirmatory evidence (based on methodologic assessment of subgroup analysis). Two studies provided exploratory evidence, and the remaining 7 provided insufficient evidence as they did not use an explicit interaction test, did not measure subgroup factor prior to randomization, or failed to measure subgroup factors by adequate (reliable and valid) measurements (table 3 ).

Of the 17 observational studies, 5 were of high methodologic quality, 10 were medium quality, and 2 were low quality (table 4).

Overall quality of evidence. The GRADE assessment resulted in an initial rating of the evidence for specific factors based on the phase of investigation of the studies. The majority of included studies consisted of phase 1 , described as exploratory studies. ${ }^{15}$ We did not rate any factors as overall high-quality evidence, as none of our factors had been investigated in a large number of cohort studies that were designed to confirm a hypothesized independent effect of the factor on the outcome (phase 2 study) or to test a conceptual model, which explains its underlying mechanisms (phase 3 study). We did not upgrade the quality of any factor for a dose response effect or a large effect size.

The initial rating per factor was further downgraded, as applicable, based on the methodologic 
Table 1 Characteristics of included studies

\begin{tabular}{|c|c|c|c|c|c|c|c|c|}
\hline $\begin{array}{l}\text { Author and } \\
\text { year }\end{array}$ & Country & $\begin{array}{l}\text { Study } \\
\text { sample size }\end{array}$ & $\begin{array}{l}\text { Description of } \\
\text { intervention (and control } \\
\text { group) if applicable }\end{array}$ & $\begin{array}{l}\text { Type of } \\
\text { headache }\end{array}$ & Study type & $\begin{array}{l}\text { Phase of } \\
\text { investigation }\end{array}$ & $\begin{array}{l}\text { Prognostic } \\
\text { factor type }\end{array}$ & $\begin{array}{l}\text { Methodologic } \\
\text { quality }\end{array}$ \\
\hline Boe 2007 & Norway & 102 & Prednisolone or placebo & $\mathrm{CH}$ & $\begin{array}{l}\text { RCT with subgroup } \\
\text { analysis }\end{array}$ & 1 & $\begin{array}{l}\text { Predictor of } \\
\text { outcome }\end{array}$ & + \\
\hline Boe 2009 & Norway & 80 & Prednisolone or placebo & $\begin{array}{l}\mathrm{CDH} \text { (with } \\
\mathrm{MO} \text { ) }\end{array}$ & $\begin{array}{l}\text { RCT with subgroup } \\
\text { analysis }\end{array}$ & 1 & $\begin{array}{l}\text { Predictor of } \\
\text { outcome }\end{array}$ & + \\
\hline $\begin{array}{l}\text { Bromberg } \\
2012\end{array}$ & USA & 189 & $\begin{array}{l}\text { Web-based behavioral } \\
\text { intervention vs waiting } \\
\text { list }\end{array}$ & $\mathrm{CM}$ & $\begin{array}{l}\text { RCT with subgroup } \\
\text { analysis }\end{array}$ & 1 & $\begin{array}{l}\text { Predictor of } \\
\text { outcome }\end{array}$ & ++ \\
\hline Castien 2011 & Netherlands & 82 & $\begin{array}{l}\text { Manual therapy or usual } \\
\text { care }\end{array}$ & СТTH & $\begin{array}{l}\text { RCT with subgroup } \\
\text { analysis }\end{array}$ & 1 & $\begin{array}{l}\text { Predictor of } \\
\text { outcome }\end{array}$ & + \\
\hline Ellis 2004 & UK & 401 & $\begin{array}{l}\text { Acupuncture or usual } \\
\text { care }\end{array}$ & $\mathrm{CH}$ & $\begin{array}{l}\text { RCT with subgroup } \\
\text { analysis }\end{array}$ & 1 & Moderator & + \\
\hline Holroyd 2009 & USA & 203 & $\begin{array}{l}\text { Placebo vs tricyclic } \\
\text { antidepressant } \\
\text { medication vs cognitive } \\
\text { behavioral stress } \\
\text { management therapy } \\
\text { with placebo vs stress } \\
\text { management therapy }+ \\
\text { antidepressant } \\
\text { medication }\end{array}$ & CTTH & $\begin{array}{l}\text { RCT with subgroup } \\
\text { analysis }\end{array}$ & 3 & $\begin{array}{l}\text { Moderator/ } \\
\text { mediator }\end{array}$ & +++ \\
\hline $\begin{array}{l}\text { Schulte- } \\
\text { Mattler } 2004\end{array}$ & Germany & 107 & $\begin{array}{l}\text { Botulinum toxin A vs } \\
\text { placebo }\end{array}$ & CTTH & $\begin{array}{l}\text { RCT with subgroup } \\
\text { analysis }\end{array}$ & 1 & $\begin{array}{l}\text { Predictor of } \\
\text { outcome }\end{array}$ & + \\
\hline Yang 2011 & Taiwan & 66 & $\begin{array}{l}\text { Acupuncture vs } \\
\text { topiramate }\end{array}$ & $\mathrm{CM}$ & $\begin{array}{l}\text { RCT with subgroup } \\
\text { analysis }\end{array}$ & 1 & $\begin{array}{l}\text { Predictor of } \\
\text { outcome }\end{array}$ & + \\
\hline Yang 2013 & Taiwan & 66 & $\begin{array}{l}\text { Acupuncture vs } \\
\text { topiramate }\end{array}$ & $\mathrm{CM}$ & $\begin{array}{l}\text { RCT with subgroup } \\
\text { analysis }\end{array}$ & 1 & Moderator & ++ \\
\hline Yurekeli 2008 & Turkey & 70 & $\begin{array}{l}\text { Sodium valproate vs } \\
\text { placebo }\end{array}$ & $\mathrm{CDH}$ & $\begin{array}{l}\text { RCT with subgroup } \\
\text { analysis }\end{array}$ & 1 & $\begin{array}{l}\text { Predictor of } \\
\text { outcome }\end{array}$ & + \\
\hline Bigal 2005 & USA & 176 & Prophylactic medication & $\mathrm{CM}$ & $\begin{array}{l}\text { Observational cohort } \\
\text { (clinic-based) }\end{array}$ & 2 & $\begin{array}{l}\text { Predictor of } \\
\text { outcome }\end{array}$ & ++ \\
\hline Buse 2011 & USA & 7,169 & NA & $\mathrm{CM}$ & $\begin{array}{l}\text { Observational cohort } \\
\text { (population-based) }\end{array}$ & 1 & $\begin{array}{l}\text { Predictor of } \\
\text { prognosis }\end{array}$ & +++ \\
\hline Eross 2005 & USA & 61 & Botulinum toxin $\mathrm{A}$ & $\mathrm{CM}$ & Open-label & 1 & $\begin{array}{l}\text { Predictor of } \\
\text { outcome }\end{array}$ & ++ \\
\hline $\begin{array}{l}\text { Fontanillas } \\
2010\end{array}$ & Spain & 72 & Prophylactic medication & $\begin{array}{l}\mathrm{CDH} \text { (with } \\
\mathrm{MO} \text { ) }\end{array}$ & $\begin{array}{l}\text { Long-term outcome } \\
\text { study }\end{array}$ & 1 & $\begin{array}{l}\text { Predictor of } \\
\text { outcome }\end{array}$ & + \\
\hline Gaul 2011 & Germany & 841 & NA & $\mathrm{CH}$ & $\begin{array}{l}\text { Long-term outcome } \\
\text { study }\end{array}$ & 1 & $\begin{array}{l}\text { Predictor of } \\
\text { outcome }\end{array}$ & +++ \\
\hline Houle 2012 & USA & 55 & NA & $\mathrm{CH}$ & Observational cohort & 2 & $\begin{array}{l}\text { Predictor of } \\
\text { prognosis }\end{array}$ & +++ \\
\hline $\begin{array}{l}\text { Katsarava } \\
2003\end{array}$ & Germany & 98 & NA & $\mathrm{CH}$ & $\begin{array}{l}\text { Long-term outcome } \\
\text { study }\end{array}$ & 1 & $\begin{array}{l}\text { Predictor of } \\
\text { outcome }\end{array}$ & ++ \\
\hline $\begin{array}{l}\text { Katsarava } \\
2004\end{array}$ & Germany & 96 & NA & $\mathrm{CH}$ & $\begin{array}{l}\text { Long-term outcome } \\
\text { study }\end{array}$ & 1 & $\begin{array}{l}\text { Predictors of } \\
\text { outcome }\end{array}$ & ++ \\
\hline Louter 2013 & Netherlands & 2,331 & NA & $\mathrm{CM}$ & Observational cohort & 1 & $\begin{array}{l}\text { Predictor of } \\
\text { prognosis }\end{array}$ & ++ \\
\hline Lu 2001 & Taiwan & 108 & NA & $\mathrm{CDH}$ & Observational cohort & 1 & $\begin{array}{l}\text { Predictor of } \\
\text { prognosis }\end{array}$ & ++ \\
\hline Luconi 2007 & Italy & 168 & Prophylactic medication & $\mathrm{CM}$ & $\begin{array}{l}\text { Observational cohort } \\
\text { (clinic-based) }\end{array}$ & 2 & $\begin{array}{l}\text { Predictor of } \\
\text { outcome }\end{array}$ & ++ \\
\hline $\begin{array}{l}\text { Lundqvist } \\
2011\end{array}$ & Norway & 195 & NA & $\mathrm{CH}$ & Observational cohort & 2 & $\begin{array}{l}\text { Predictor of } \\
\text { prognosis }\end{array}$ & ++ \\
\hline Matthew 2007 & USA & 82 & Botulinum toxin $\mathrm{A}$ & $\mathrm{CDH}$ & Open-label & 1 & $\begin{array}{l}\text { Predictor of } \\
\text { outcome }\end{array}$ & + \\
\hline Seok 2006 & Korea & 136 & Prophylactic medication & $\mathrm{CDH}$ & Open-label & 1 & $\begin{array}{l}\text { Predictor of } \\
\text { outcome }\end{array}$ & ++ \\
\hline Tribl 2001 & Austria & 55 & NA & $\mathrm{CDH}$ & $\begin{array}{l}\text { Long-term outcome } \\
\text { study }\end{array}$ & 1 & $\begin{array}{l}\text { Predictor of } \\
\text { outcome }\end{array}$ & ++ \\
\hline
\end{tabular}


Table 1 Continued

\begin{tabular}{|c|c|c|c|c|c|c|c|c|}
\hline $\begin{array}{l}\text { Author and } \\
\text { year }\end{array}$ & Country & $\begin{array}{l}\text { Study } \\
\text { sample size }\end{array}$ & $\begin{array}{l}\text { Description of } \\
\text { intervention (and control } \\
\text { group) if applicable }\end{array}$ & $\begin{array}{l}\text { Type of } \\
\text { headache }\end{array}$ & Study type & $\begin{array}{l}\text { Phase of } \\
\text { investigation }\end{array}$ & $\begin{array}{l}\text { Prognostic } \\
\text { factor type }\end{array}$ & $\begin{array}{l}\text { Methodologic } \\
\text { quality }\end{array}$ \\
\hline $\begin{array}{l}\text { Zidverc- } \\
\text { Trajkovic } 2007\end{array}$ & Serbia & 240 & Prophylactic medication & $\begin{array}{l}\mathrm{CH} \text { (with } \\
\mathrm{MO} \text { ) }\end{array}$ & Open-label & 1 & $\begin{array}{l}\text { Predictor of } \\
\text { outcome }\end{array}$ & +++ \\
\hline Zwart 2003 & Norway & 32,067 & NA & $\mathrm{CH}$ & Observational cohort & 2 & $\begin{array}{l}\text { Predictor of } \\
\text { prognosis }\end{array}$ & +++ \\
\hline
\end{tabular}


overuse; NA = not applicable; RCT = randomized controlled trial.

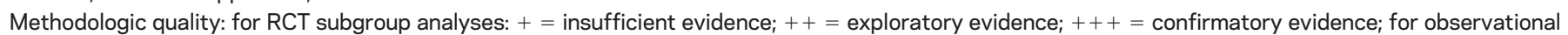
studies: $+=$ low quality; $++=$ medium quality $;++=$ high quality.

quality of the studies and potential inconsistency, indirectness, and imprecision of findings (table 5).

We present prognostic factors identified together regardless of the type of factor (predictor or moderator, mediator).

Potential prognostic factors with moderate-quality evidence. Depression and anxiety. Depression was consistently found to be a predictor of poor outcome. Depression predicted higher influence of headaches on normal daily life and ability to function (Headache Impact Test [HIT]-6 scores $)^{27}$ and having allodynia, more migraine days, a larger change in migraine days from baseline to follow-up and more medication days at follow-up, ${ }^{34}$ lower response to prophylactic treatment, ${ }^{35}$ lower response to prednisolone + withdrawal therapy, ${ }^{25}$ and one study found that there was reduced response to placebo treatment when anxiety or mood diagnosis was present. ${ }^{20}$ However, the same study also found that people with mood disorder benefit more from antidepressant therapy and behavioral therapy.

Medication overuse. Medication overuse was also consistently found to predict poor prognosis. Medication overuse predicted the presence of chronic headache at follow-up, ${ }^{5,36,38,41}$ increase in headache days, ${ }^{34}$ lower quality of life, ${ }^{29}$ and unsuccessful detoxification. ${ }^{29,40}$

Headache management self-efficacy. Only one study ${ }^{20}$ investigated a potential effect mediator within its analysis. The authors measured HMSE during the intervention (2 months postrandomization) and found it mediated the effects of antidepressant therapy and stress management therapy on headacherelated disability and headache activity.

Sleep and stress. One study found that poor sleep and high stress predict headache severity in individuals with chronic headache. Conversely, high sleep and low stress showed a protective effect. ${ }^{31}$

Potential prognostic factors with low-quality evidence. Higher expectations. In both the acupuncture and topiramate groups in one study, ${ }^{23}$ it was found that those with a higher general expectation of treatment showed a greater reduction in moderate or severe headache days compared to those with lower expectations.

Body mass index. A higher body mass index (BMI) did not predict more severe HIT-6 scores, ${ }^{27}$ having allodynia, headache frequency, medication use, ${ }^{34}$ or response to multidisciplinary treatment. ${ }^{30}$ However,

Table 2 Risk of bias assessment in randomized controlled trials

$\begin{array}{llllll} & \begin{array}{l}\text { 1. Did the study have an } \\ \text { adequate randomization } \\ \text { sequence? }\end{array} & \begin{array}{l}\text { 2. Was allocation } \\ \text { concealment carried } \\ \text { out? }\end{array} & \begin{array}{l}\text { 3. Were withdrawals } \\ \text { and dropouts explained? }\end{array} & \begin{array}{l}\text { 4. Was outcome } \\ \text { assessment blinded? }\end{array} & \begin{array}{l}\text { 5. Sufficient numbers } \\ \text { (>20 in each arm)? }\end{array} \\ \begin{array}{l}\text { Author and year } 2007 \\ \text { Boe } 2009\end{array} & \checkmark & \checkmark & \checkmark & \checkmark & \checkmark \\ \text { Score }\end{array}$

Studies scoring 4-5 points were considered higher quality (low risk of bias); studies scoring 2-3 were considered medium quality (moderate risk of bias). 
Table 3 Quality assessment of randomized controlled trial subgroup analyses using methodologic criteria by Pincus et al. ${ }^{13}$

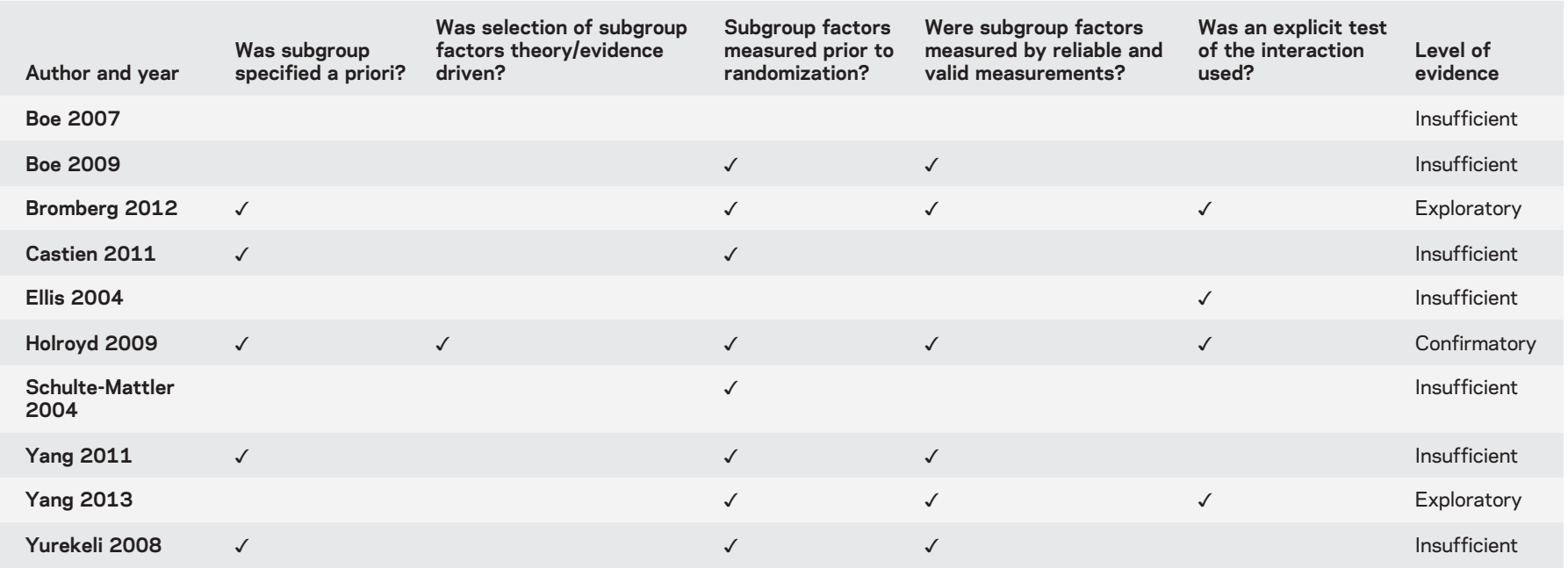

Confirmatory evidence: Studies complying with all 5 criteria; exploratory evidence: studies complying with criteria 3, 4, and 5 . All other studies were classified as providing insufficient evidence.

conversely, one study found that a higher BMI predicted a better response to preventive treatment and favorable HIT-6 scores postintervention. ${ }^{25}$

Age. Older age had no effect on the response to interventions, including prophylactic treatment, ${ }^{25,35}$ webbased behavioral intervention, ${ }^{17}$ and acupuncture. ${ }^{23}$ Older age was also not associated with reverting from chronic to episodic migraine, ${ }^{38}$ response to medication overuse, ${ }^{29}$ having allodynia, ${ }^{34}$ headache frequency or intensity, ${ }^{39}$ or headache-related disability. ${ }^{20}$

In contrast, older age was found to predict worse HIT-6 scores, ${ }^{27}$ later chronic daily headache $(\mathrm{CDH}),{ }^{5}$ lower response to botulinum toxin $\mathrm{A}$ treatment, ${ }^{28}$ unsuccessful detoxification, ${ }^{40}$ and more weekly analgesics used. ${ }^{41}$ Conversely, one study found that older patients had better outcomes from multidisciplinary treatment. $^{30}$

Age at onset. Older age at onset was a predictor for fewer migraine days, less use of medication at followup, ${ }^{34}$ and better response to prophylactic medication, ${ }^{40}$ but did not predict response to prophylactic treatment in another study. ${ }^{35}$

Baseline headache-related disability. Higher symptoms at baseline were found to predict higher rates of disability $^{27}$ and the transition to $\mathrm{CDH} .{ }^{5}$ In contrast, higher symptoms and disability at baseline were associated with successful detoxification, ${ }^{40}$ and showed no significant association with response to treatment. ${ }^{35}$

Baseline beadache frequency. The evidence from 7 studies was contradictory. Headache frequency did not differ between responders and nonresponders to prophylactic treatment, ${ }^{35}$ and higher baseline frequency did not predict reverting to episodic migraine from chronic migraine after treatment. ${ }^{38}$ It was not related to subsequent HIT-6 scores ${ }^{26}$ in patients with chronic migraine. Conversely, higher headache frequency was related to later persistent chronic headache, ${ }^{5}$ was found to increase the risk of having allodynia and more medication use days, but was also associated with a reduction in migraine days at followup. ${ }^{34}$ Two studies found that higher frequency predicts favorable response to detoxification ${ }^{40}$ and to multidisciplinary treatment. ${ }^{30}$

Baseline headache severity. One study ${ }^{20}$ found that when looking at headache index as outcome, those with more severe headache had better treatment effects from stress management and antidepressant therapy than those with less severe headache. Another study ${ }^{23}$ found that those with more than 20 moderate or severe headache days a month had a greater reduction in the mean number of moderate or severe headache days after acupuncture.

Employment. One study found that those who were employed had higher response rates to treatment compared to those on medical leave, ${ }^{40}$ but 2 studies ${ }^{25,38}$ found employment made no difference for persistence of $\mathrm{CDH}$ and number headache days at follow-up.

The evidence for all other factors was graded as very low quality (table 5).

DISCUSSION Summary of results. In this review, we aimed to systematically identify predictors, moderators, and mediators of prognosis and outcomes in chronic headache from prospective studies, including prospective cohorts and trials of preventive interventions. Our findings suggest with moderate-quality evidence that depression/anxiety, medication overuse, poor sleep, high stress, and low HMSE are associated with worse outcomes. Lower-quality evidence suggests that higher expectations, age, age at onset, headache 


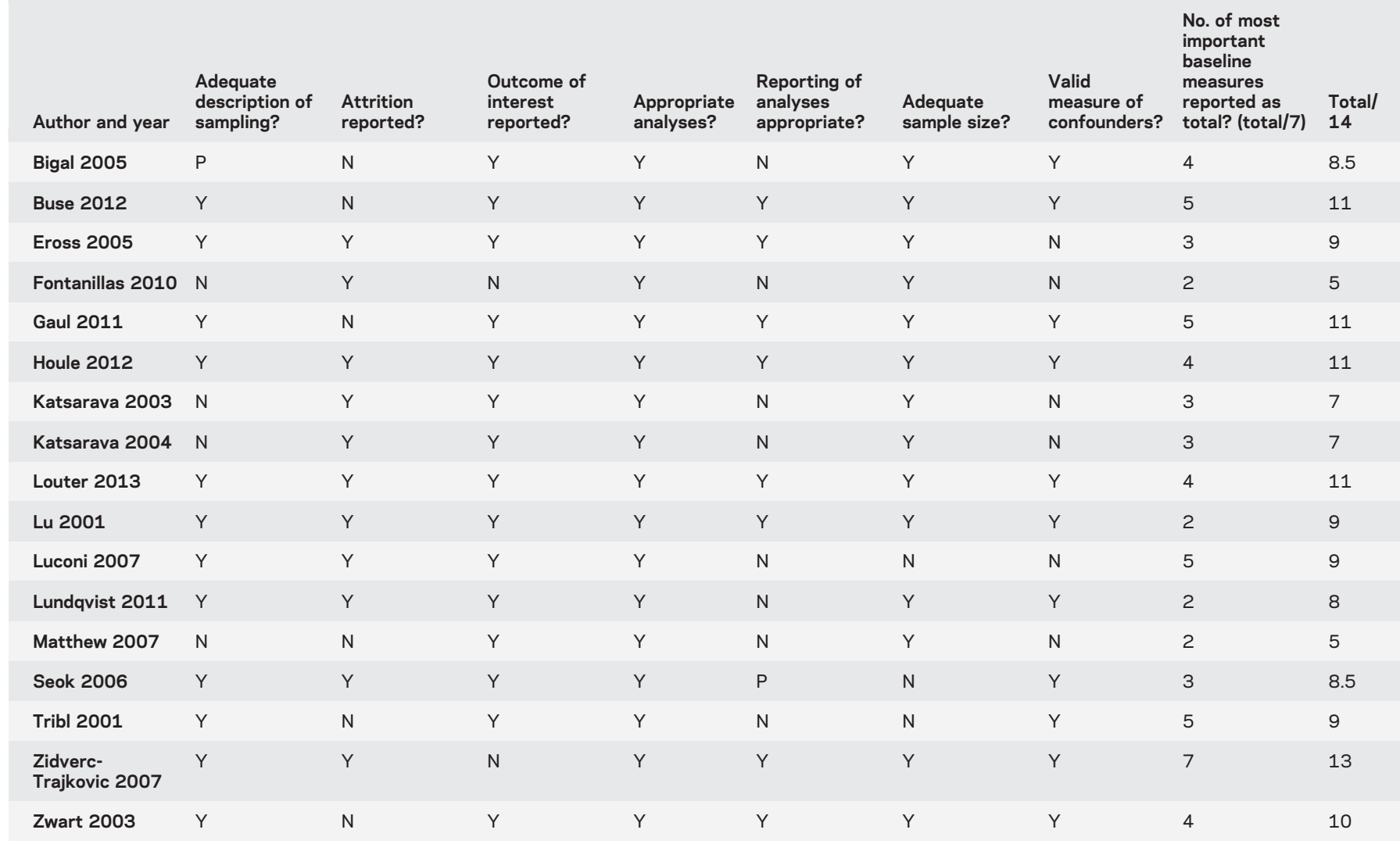

$\leq 5$ Points = low quality; $6-9$ points $=$ medium quality; $\geq 10$ points $=$ high quality; $\mathrm{N}=$ no $(0$ points $) ; \mathrm{P}=$ partially $(0.5$ point $) ; \mathrm{Y}=$ yes $(1$ point $)$.

frequency, intensity, BMI, disability scores, and employment are potential predictors. The highestquality evidence we found suggests that psychosocial factors, anxiety and mood disorder, sleep and stress, and HMSE are potential prognostic factors. This is an important finding, as these factors are all potentially modifiable. Specifically, groups with low mood (anxiety and mood disorder) appear to respond better to antidepressants and stress management therapy. In the absence of anxiety and mood disorder, higher HMSE improves treatment outcomes. We also found some evidence that more positive expectations about treatment are associated with better outcomes. Our results also suggest that older patients and those with more severe headache might benefit from multidisciplinary treatment, which can address comorbidity and specifically tailor treatment to more complex needs. However, owing to the limited number of studies, it was not possible to identify prognostic factors from studies providing high-quality evidence. The number of studies identified matching our inclusion criteria for this review was low and overall quality of evidence was moderate, low, or very low, implying that confidence in the estimate is low.

Comparison with other studies and reviews. While most of the evidence on prognostic factors in the field focuses on studying the chronification process of headache or risk factors of developing chronic headache from episodic headache, we looked at patients with a diagnosis of chronic headache at baseline. Our findings indicate that there is potential for behavioral interventions targeting psychosocial prognostic factors in people living with chronic headache. Our results are in line with Smitherman et al., ${ }^{42}$ who suggest that depression, anxiety, and insomnia should be assessed in every treatment-seeking headache patient, particularly those with frequent attacks. ${ }^{42}$ Our finding that self-efficacy can mediate treatment effects in chronic headache is in line with Peck and Smitherman, ${ }^{43}$ who assessed HMSE as mediator for the relationship between headache severity and disability in a population of predominantly nonchronic headache sufferers. Self-efficacy has also been found to be associated with improvement of outcomes in other chronic pain conditions. ${ }^{44-46}$

Strengths and limitations of this review. The strength of this review is that we only included prospective longitudinal study types to ensure reliability and quality of results. These study designs are less prone to some types of bias and can most strongly suggest causation. ${ }^{47}$ For the widest feasible scope and to identify all potential prognostic factors, we included RCTs with subgroup analyses, which are the ideal study 
Table 5 Grading of Recommendations Assessment, Development and Evaluation (GRADE) evidence profile of overall quality

\begin{tabular}{|c|c|c|c|c|c|c|c|c|c|c|c|}
\hline \multirow[b]{2}{*}{ Potential prognostic factors } & \multirow[b]{2}{*}{$\begin{array}{l}\text { No. of } \\
\text { studies }\end{array}$} & \multicolumn{4}{|l|}{ GRADE factors } & \multirow[b]{2}{*}{$\begin{array}{l}\text { No. of } \\
\text { participants }\end{array}$} & \multicolumn{3}{|c|}{$\begin{array}{l}\text { Univariate or } \\
\text { multivariate }\end{array}$} & \multirow[b]{2}{*}{$\begin{array}{l}\text { Phase of } \\
\text { investigation }\end{array}$} & \multirow[b]{2}{*}{$\begin{array}{l}\text { Overall } \\
\text { quality }\end{array}$} \\
\hline & & Study limitations & Inconsistency & Indirectness & Imprecision & & + & 0 & - & & \\
\hline \multicolumn{12}{|l|}{ Psychosocial factors } \\
\hline Depression and anxiety & 5 & $\checkmark$ & $\checkmark$ & $\mathrm{x}$ & $\checkmark$ & 9,951 & & & 5 & 1 and 3 & +++ \\
\hline Employment & 3 & $\mathrm{x}$ & $\checkmark$ & $\mathrm{x}$ & $\mathrm{x}$ & 456 & 1 & 2 & & 1 & ++ \\
\hline Higher expectations & 1 & $x$ & $\checkmark$ & $x$ & $x$ & 66 & 1 & & & 1 & ++ \\
\hline $\begin{array}{l}\text { Headache management self- } \\
\text { efficacy }\end{array}$ & 1 & $\checkmark$ & $\checkmark$ & $x$ & $x$ & 203 & 1 & & & 3 & +++ \\
\hline Sleep and stress & 1 & $\checkmark$ & $\checkmark$ & $\checkmark$ & $x$ & 80 & & & 1 & 2 & +++ \\
\hline \multicolumn{12}{|l|}{ Headache features } \\
\hline Allodynia & 3 & $x$ & $\checkmark$ & $x$ & $x$ & 2,479 & 1 & 1 & & 1 & + \\
\hline Muscle tenderness & 3 & $x$ & $x$ & $x$ & $x$ & 250 & 1 & 2 & & 1 & + \\
\hline Throbbing & 1 & $x$ & $\checkmark$ & $x$ & $x$ & 66 & 1 & & & 1 & + \\
\hline Unilateral headache & 2 & $x$ & $x$ & $x$ & $x$ & 148 & 1 & 1 & & 1 & + \\
\hline \multicolumn{12}{|l|}{ Demographics } \\
\hline Age at onset & 3 & $\checkmark$ & $x$ & $x$ & $x$ & 2,739 & 2 & 1 & & 1 & ++ \\
\hline BMI & 4 & $\checkmark$ & $x$ & $x$ & $\checkmark$ & 10,522 & & 3 & 1 & 1 and 2 & ++ \\
\hline Age & 15 & $\checkmark$ & $x$ & $\checkmark$ & $\checkmark$ & 43,640 & 1 & 9 & 5 & 1,2 , and 3 & ++ \\
\hline \multicolumn{12}{|l|}{ Headache characteristics } \\
\hline Migraine as subgroup & 4 & $x$ & $x$ & $x$ & $x$ & 619 & 2 & 2 & & 1 & + \\
\hline Headache severity & 2 & $x$ & $\checkmark$ & $x$ & & 269 & 2 & & & 1 and 3 & ++ \\
\hline Headache-related disability & 4 & $\checkmark$ & $x$ & $x$ & $x$ & 7,685 & & 1 & 3 & 1 and 2 & ++ \\
\hline Headache frequency & 7 & $\checkmark$ & $x$ & $x$ & $\checkmark$ & 4,000 & 2 & 3 & 2 & 1 and 2 & ++ \\
\hline Medication overuse & 7 & $\checkmark$ & $\checkmark$ & $x$ & $\checkmark$ & 36,215 & & & 7 & 1 and 2 & +++ \\
\hline Drug type overused (ergots) & 2 & $x$ & $x$ & $x$ & $x$ & 240 & 1 & & 1 & 1 & + \\
\hline Drug type overused (analgesics) & 3 & $x$ & $x$ & $x$ & $x$ & 266 & 1 & & 1 & 1 & + \\
\hline
\end{tabular}

Abbreviation: $\mathrm{BMI}=$ body mass index.

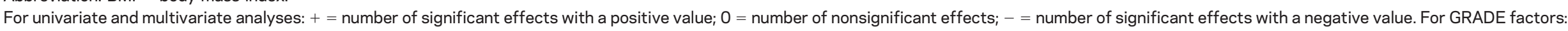
$\checkmark=$ no serious limitations; $X=$ serious limitations or unclear (unable to rate based on available information). For overall quality: $+=$ very low quality; $++=$ low quality; $+++=$ moderate quality 
design to assess potential moderators and mediators of outcome, and prospective cohort studies (including observational cohort studies, long-term outcome studies, and open-label studies), which are the best study designs to assess predictors of prognosis independent of treatment. It would have been favorable to be able to analyze predictors, moderators, and mediators separately; however, the large heterogeneity between factors measured and scarcity of data did not allow us to do this and we presented factors measured by studies together regardless of the type of prognostic factors.

We adhered to our registered protocol, thus strengthening the credibility of the evidence synthesis. We assessed the methodology of included studies with the best available tools specific to the study designs of included primary studies and judged and reported the overall quality of the evidence based on the recommendations from the GRADE Working Group. The GRADE framework adapted to prognostic factor research is the best available tool for reporting the overall quality of the evidence of the potential prognostic factors since we could not carry out meta-analysis.

With regards to included participants, we rigorously only included studies on chronic headache types, with a chronic headache diagnosis as baseline, so the results are specific to this group of patients. Most of the research in the field reports on episodic headache, which has a much higher prevalence, but prognostic factors established in episodic headache are not necessarily transferable to chronic headache patients.

Limitations regarding the interpretation of the findings from this study should be taken into consideration. As we included more than one form of chronic headache, most of our findings are subject to some indirectness, as some findings came from studies specific for chronic tension-type headache, chronic migraine, or chronic medication overuse headache, and therefore we urge some caution with generalizability of findings for all forms of chronic headache. We could not present results for each of the included diagnostic groups separately because of a scarcity of data and some of the included primary studies including mixed groups and presenting overall results.

Publication bias is one of the most common biases in systematic reviews. As suggested by Huguet et al., ${ }^{15}$ we considered publication bias to exist across all factors as we did not have determinate factors investigated in large numbers of cohort studies purposefully designed to confirm hypothesized factors, and we therefore consequently downgraded the overall evidence.

Judging the overall quality of evidence per factor was difficult, as measurements used to assess the same factors were not necessarily related to the same outcomes. Furthermore, most study samples are small and factors were measured by single studies or a small amount of studies with comparatively small patient groups assessed. The included RCTs were underpowered for moderator analysis, which creates some imprecision of results, and relevant statistics were not consistently reported. Studies with otherwise good methodology were compromised by poor methodologic quality of their subgroup analysis. We specifically note the lack of RCTs that carried out prespecified subgroup analysis, which would provide higher-quality evidence, and the lack of theoretical framework of moderator and mediator analyses. ${ }^{43,48}$ In this review, there was only one study that conducted prespecified subgroup analysis, and its reporting was difficult to interpret. The authors concluded that the moderator was significantly associated with treatment outcome before, during, and after treatment, but it was not clear if the significance was driven by the difference between placebo and the other 3 treatments across treatment time or the difference within treatment across treatment time. The mediator analysis reported in the same article adjusted for some covariates but there remains the potential for confounding of the mediator outcome association by other factors. Most of the included cohort studies did not specify the relationships they were testing a priori, and were therefore defined as phase I explanatory studies.

Implications for future research and clinical practice. Overall this review identified several potentially modifiable prognostic factors in chronic headache. However, the review findings also indicate that the evidence is scarce. No high-quality evidence was provided for any of the potential prognostic factors; therefore, no definite clinical conclusion can be drawn about factors predicting the prognosis of patients living with chronic headache or factors that influence or predict treatment response. The implication is that future research on prognostic factors in chronic headache should be ideally conducted as large, prospective, registered, and protocol-based studies with sufficient study populations and transparent reporting. Prespecified prediction analyses in large cohort studies are needed to confirm potential predictors. Further, a priori analysis plans for subgroups in RCTs are needed to assess moderators and mediators of treatment outcome.

\section{AUTHOR CONTRIBUTIONS}

Katrin Probyn: review concept and design, screening of studies, data extraction, quality assessment, interpretation of data, writeup. Hannah Bowers: data extraction, quality assessment, interpretation of data, writeup. Fiona Caldwell: review concept and design, screening of studies, data extraction. Dipesh Mistry: quality assessment, data extraction, interpretation of data. Martin Underwood: review concept and design, critical revision of manuscript. Manjit Matharu: review concept and design, critical 
revision of manuscript. Tamar Pincus: project leader, review concept and design, study supervision, interpretation of data, critical revision of manuscript.

\section{ACKNOWLEDGMENT}

Samantha Johnson (University of Warwick, academic support librarian) conducted the literature searches for this review.

\section{STUDY FUNDING}

This research was funded by the NIHR Programme Grants for Applied Research programme (RP-PG-1212-20018). The views expressed in this publication are those of the authors and not necessarily those of the NHS, the NIHR, or the Department of Health.

\section{DISCLOSURE}

K. Probyn, H. Bowers, F. Caldwell, and D. Mistry report no disclosures relevant to the manuscript. M. Underwood reports grants from National Institute for Health Research, personal fees from National Institute for Health and Care Excellence, grants from Arthritis Research UK, and personal fees from National Institute for Health Research, outside the submitted work, and is Chair of the guideline development group that produced the 2012 NICE headache guidelines. He has completed trials of manual therapy, group exercise, and a cognitive behavioral approach as treatments for low back pain. M. Matharu and T. Pincus report no disclosures relevant to the manuscript. Go to Neurology.org for full disclosures.

Received December 8, 2016. Accepted in final form March 15, 2017.

\section{REFERENCES}

1. The International Classification of Headache Disorders, 3rd edition (beta version). Cephalalgia 2013;33:629-808.

2. Buse DC, Manack AN, Fanning K. Chronic migraine prevalence, disability, and sociodemographic factors: results from the American Migraine Prevalence and Prevention Study. Headache 2012;52:1456-1470.

3. Natoli JL, Manack A, Lipton RB, et al. Global prevalence of chronic migraine: a systematic review. Cephalalgia 2010;30:599-609.

4. Schwartz BS, Stewart WF, Simon D, Lipton RB. Epidemiology of tension-type headache. JAMA 1998;279:381-383.

5. Lu SR, Fuh JL, Chen WT, Juang KD, Wang SJ. Chronic daily headache in Taipei, Taiwan: prevalence, follow-up and outcome predictors. Cephalalgia 2001;21:980-986.

6. Smitherman TA, Burch R, Sheikh H, Loder E. The prevalence, impact, and treatment of migraine and severe headaches in the United States: a review of statistics from national surveillance studies. Headache 2013;53:427-436.

7. Monninkhof E, van $\operatorname{der} \mathrm{Aa} M$, van der Valk P, et al. A qualitative evaluation of a comprehensive self-management programme for COPD patients: effectiveness from the patients' perspective. Patient Education Couns 2004;55: 177-184.

8. Turk DC. The potential of treatment matching for subgroups of patients with chronic pain: lumping versus splitting. Clin J Pain 2005;21:44-55.

9. Kraemer HC, Wilson GT, Fairburn CG, Agras WS. Mediators and moderators of treatment effects in randomized clinical trials. Arch Gen Psychiatry 2002;59:877-883.

10. Kennedy A, Reeves D, Bower P, et al. The effectiveness and cost effectiveness of a national lay-led self care support programme for patients with long-term conditions: a pragmatic randomised controlled trial. J Epidemiol Community Health 2007;61:254-261.

11. Miles CL, Pincus T, Carnes D, et al. Can we identify how programmes aimed at promoting self-management in musculoskeletal pain work and who benefits? A systematic review of sub-group analysis within RCTs. Eur J Pain 2011;15:1-11.

12. Higgins J, Green S. Cochrane Handbook for Systematic Reviews of Interventions, version 5.0.1. London: Cochrane Collaboration; 2008.

13. Pincus T, Miles C, Froud R, Underwood M, Carnes D, Taylor SJ. Methodological criteria for the assessment of moderators in systematic reviews of randomised controlled trials: a consensus study. BMC Med Res Methodol 2011;11:14.

14. Hayden JA, Cote P, Bombardier C. Evaluation of the quality of prognosis studies in systematic reviews. Ann Intern Med 2006;144:427-437.

15. Huguet AHJ, Stinson J, McGrath PJ, Chambers CT, Tougas ME, Wozney L. Judging the quality of evidence in reviews of prognostic factor research: adapting the GRADE framework. Syst Rev 2013;2:71.

16. Boe MG, Mygland A, Salvesen R. Prednisolone does not reduce withdrawal headache: a randomized, double-blind study. Neurology 2007;69:26-31.

17. Bromberg J, Wood ME, Black RA, Surette DA, Zacharoff KL, Chiauzzi EJ. A randomized trial of a web-based intervention to improve migraine self-management and coping. Headache 2012;52:244-261.

18. Castien RF, van der Windt DA, Grooten A, Dekker J. Effectiveness of manual therapy for chronic tension-type headache: a pragmatic, randomised, clinical trial. Cephalalgia 2011;31:133-143.

19. Ellis N, Fisher P, McCarney R, et al. Acupuncture for chronic headache in primary care: large, pragmatic, randomised trial. Br Med J 2004;328:744-747.

20. Holroyd KA, Labus JS, Carlson B. Moderation and mediation in the psychological and drug treatment of chronic tension-type headache: the role of disorder severity and psychiatric comorbidity. Pain 2009;143:213-222.

21. Schulte-Mattler WJ, Krack P; BoNTTH Study Group. Treatment of chronic tension-type headache with botulinum toxin A: a randomized, double-blind, placebocontrolled multicenter study. Pain 2004;109:110-114.

22. Yang CP, Chang MH, Liu PE, et al. Acupuncture versus topiramate in chronic migraine prophylaxis: a randomized clinical trial. Cephalalgia 2011;31:1510-1521.

23. Yang CP, Chang MH, Li TC, Hsieh CL, Hwang KL, Chang $\mathrm{HH}$. Predicting prognostic factors in a randomized controlled trial of acupuncture versus topiramate treatment in patients with chronic migraine. Clin J Pain 2013;29: 982-987.

24. Yurekli VA, Akhan G, Kutluhan S, Uzar E, Koyuncuoglu HR, Gultekin F. The effect of sodium valproate on chronic daily headache and its subgroups. J Headache Pain 2008;9:37-41.

25. Bøe MG, Salvesen R, Mygland Å. Chronic daily headache with medication overuse: predictors of outcome 1 year after withdrawal therapy. Eur J Neurol 2009;16:705-712.

26. Bigal ME, Gironda M, Tepper SJ, et al. Headache prevention outcome and body mass index. Cephalalgia 2006; 26:445-450.

27. Buse D, Manack A, Serrano D, et al. Headache impact of chronic and episodic migraine: results from the American Migraine Prevalence and Prevention study. Headache 2012;52:3-17.

28. Eross EJ, Gladstone JP, Lewis S, Rogers R, Dodick DW. Duration of migraine is a predictor for response to botulinum toxin type A. Headache 2005;45:308-314. 
29. Fontanillas N, Colas R, Munoz P, Oterino A, Pascual J. Long-term evolution of chronic daily headache with medication overuse in the general population. Headache 2010; 50:981-988.

30. Gaul C, Bromstrup J, Fritsche G, Diener HC, Katsarava Z. Evaluating integrated headache care: a one-year followup observational study in patients treated at the Essen headache centre. BMC Neurol 2011:11.

31. Houle TT, Butschek RA, Turner DP, Smitherman TA, Rains JC, Penzien DB. Stress and sleep duration predict headache severity in chronic headache sufferers. Pain 2012;153:2432-2440.

32. Katsarava Z, Limmroth V, Finke M, Diener HC, Fritsche G. Rates and predictors for relapse in medication overuse headache: a 1-year prospective study. Neurology 2003;60: 1682-1683.

33. Katsarava Z, Muessig M, Dzagnidze A, Fritsche G, Diener HC, Limmroth V. Medication overuse headache: rates and predictors for relapse in a 4 -year prospective study. Cephalalgia 2005;25:12-15.

34. Louter MA, Bosker JE, van Oosterhout WP, van Z EW, et al. Cutaneous allodynia as a predictor of migraine chronification. Brain 2013;136:3489-3496.

35. Luconi R, Bartolini M, Taffi R, et al. Prognostic significance of personality profiles in patients with chronic migraine. Headache 2007;47:1118-1124.

36. Lundqvist C, Grande RB, Aaseth K, Russell MB. Dependence scores predict prognosis of medication overuse headache: a prospective cohort from the Akershus study of chronic headache. Pain 2012;153:682-686.

37. Mathew NT, Kailasam J, Meadors L. Predictors of response to botulinum toxin type A (BoNTA) in chronic daily headache. Headache 2008;48:194-200.

38. Seok JI, Cho HI, Chung CS. From transformed migraine to episodic migraine: reversion factors. Headache 2006; 46 : 1186-1190.
39. Tribl GG, Schnider P, Wober C, et al. Are there predictive factors for long-term outcome after withdrawal in druginduced chronic daily headache? Cephalalgia 2001;21: 691-696.

40. Zidverc-Trajkovic J, Pekmezovic T, Jovanovic Z, et al. Medication overuse headache: clinical features predicting treatment outcome at 1-year follow-up. Cephalalgia 2007; 27:1219-1225

41. Zwart JA, Dyb G, Hagen K, Svebak S, Holmen J. Analgesic use: a predictor of chronic pain and medication overuse headache: the Head-HUNT Study. Neurology 2003; 61:160-164.

42. Smitherman TA, Penzien DB, Rains JC, Nicholson RA, Houle TT. Headache. Göttingen: Hogrefe; 2015.

43. Peck KR, Smitherman TA. Mediator variables in headache research: methodological critique and exemplar using self-efficacy as a mediator of the relationship between headache severity and disability. Headache 2015;55:1102-1111.

44. Buckelew SP, Huyser B, Hewett JE, et al. Self-efficacy predicting outcome among fibromyalgia subjects. Arthritis Care Res 1996;9:97-104.

45. Costa Lda C, Maher CG, McAuley JH, Hancock MJ, Smeets RJ. Self-efficacy is more important than fear of movement in mediating the relationship between pain and disability in chronic low back pain. Eur J Pain 2011;15:213-219.

46. Sharma L, Cahue S, Song J, Hayes K, Pai YC, Dunlop D. Physical functioning over three years in knee osteoarthritis: role of psychosocial, local mechanical, and neuromuscular factors. Arthritis Rheum 2003;48:3359-3370.

47. Thiese MS. Observational and interventional study design types; an overview. Biochemia Med 2014;24:199-210.

48. Nicholson RA, Hursey KG, Nash JM. Moderators and mediators of behavioral treatment for headache. Headache 2005;45:513-519. 


\section{Neurology}

\section{Prognostic factors for chronic headache: A systematic review \\ Katrin Probyn, Hannah Bowers, Fiona Caldwell, et al. \\ Neurology 2017;89;291-301 Published Online before print June 14, 2017 \\ DOI 10.1212/WNL.0000000000004112}

This information is current as of June 14, 2017

Updated Information \&
Services

Supplementary Material

\section{References}

Citations

Subspecialty Collections

Permissions \& Licensing

Reprints including high resolution figures, can be found at:

http://n.neurology.org/content/89/3/291.full

Supplementary material can be found at:

http://n.neurology.org/content/suppl/2017/06/14/WNL.0000000000004 112.DC1

http://n.neurology.org/content/suppl/2017/06/14/WNL.0000000000004 112.DC2

http://n.neurology.org/content/suppl/2017/06/29/WNL.0000000000004 112.DC3

This article cites 45 articles, 5 of which you can access for free at: http://n.neurology.org/content/89/3/291.full\#ref-list-1

This article has been cited by 6 HighWire-hosted articles: http://n.neurology.org/content/89/3/291.full\#\#otherarticles

This article, along with others on similar topics, appears in the following collection(s):

\section{Migraine}

http://n.neurology.org/cgi/collection/migraine

Tension headache

http://n.neurology.org/cgi/collection/tension_headache

Information about reproducing this article in parts (figures,tables) or in its entirety can be found online at:

http://www.neurology.org/about/about_the_journal\#permissions

Information about ordering reprints can be found online:

http://n.neurology.org/subscribers/advertise

Neurology ${ }^{\circledR}$ is the official journal of the American Academy of Neurology. Published continuously since 1951, it is now a weekly with 48 issues per year. Copyright Copyright ( 2017 The Author(s). Published by Wolters Kluwer Health, Inc. on behalf of the American Academy of Neurology.. All rights reserved. Print ISSN: 0028-3878. Online ISSN: 1526-632X.



